\title{
IMPLEMENTATION OF DRUG SUBSTITUTION THERAPY IN GEORGIA
}

\author{
Khatuna Todadze, Gela Lezhava \\ Research Institute on Addiction, Tbilisi, Georgia
}

\section{SUMMARY}

The geopolitical uniqueness of the regional, socioeconomic situation and the existence of territories outside the control of the national government have facilitated the spread of drug use in Georgia. A special problem is injection of opiates, in particular heroin and Subutex (buprenorphine). It has been established that among registered HIV infected individuals the main route of transmission is injecting drug use. Although the prevalence of HIV among IDUs (injecting drug user) is only 1-3\%, the high number of IDUs, and the high prevalence of hepatitis $\mathrm{C}$ in this population creates high risk of dramatic spread of HIV in Georgia. Beginning at the end of 2005, the GFATM (Global Fund against HIVIAIDS, Tuberculosis and Malaria) supported methadone substitution programmes in Georgia. At present, three programmes are functioning. At the same time, they involve 230 patients altogether. The studies carried out by the Research Institute on Addiction, with the aim to control the efficacy of pilot programmes have revealed a dramatic improvement of psychophysical state of patients, with very high rate of resocialization and decriminalization, significant diminishment of drug-related risky behaviour. Obtained results indicate high efficiency of methadone substitution programmes in Georgia, as an important tool both for treatment of opioid dependence and harm reduction. In order to obtain a more significant impact on public health substitution therapy programmes have to be further expanded.

Key words: drug use, methadone, opioid substitution therapy, Subutex, Georgia

Address for correspondence: K. Todadze, Research Institute on Addiction, 39a Vaja-Pshavela st, Tbilisi, 0177, Georgia.

E-mail: khatunatod@gol.ge

\section{INTRODUCTION}

Drug abuse and related health problems (e.g. hepatitis C and overdose), as well as social and economic consequences are critical issues that Georgia faces today. Drug use has significantly increased since early 1990s due to several reasons. On one hand, the destruction of the Soviet Union was followed by the breakdown of an anti-drug system, specific for the totalitarian state that was based on the prohibitive measures. On the other hand, unprotected borders, criminal situation and corruption have made drugs easily available. At the same time, the social-economic collapse, crisis of values in society, unemployment and social pessimism has promoted the escalation of drug use. Further, the geographic location turns Georgia into one of the important routes for transiting drugs from Asia to Europe.

Despite the fact that recently visible success has been achieved in economic development and reduction of crime, drug abuse has not decreased.

According to the information of the Research Institute on Addiction, the number of officially registered drug abusers and drug addicts increased nine times from 1990 to 2004. The number of newly registered drug users increased three times and more in 2003 in comparison to the year 1994 (1).

Today, up to 24,000 drug users are registered. But according to local experts' estimation, the real number of drug users reaches $200,000-240,000$ people (more than $4 \%$ of the population) (2). The estimated number of IDUs ranges from 70,000 to 80,000 and the quantity of drug dependent people is estimated at $25,000-30,000(2)$.

Opioids are the main injective drugs in Georgia $(1,2)$ (Fig. 1). Before 1998-99 handmade solution from raw opium and dry poppy was abused. Since 1999-2000 heroine has been on top of the list of injective drugs. In 2003 mass abuse of poppy seeds occurred, but was stopped after preventive measures were taken. The abuse of buprenorphin (Subutex) has assumed special dimensions during the last few years.

Subutex is not used for medical purposes in Georgia, but a big amount of this substance comes from foreign countries (mostly within Europe) through illegal channels. It seems that in some countries, the medical use of Subutex is not adequately controlled, due to which it appears on the "black market". In Georgia, Subutex is basically brought in by domestic citizens. Subutex dealing is a quite profitable business. In Europe, the price of 1 pill of Subutex is $€ 1$, whereas in Georgia it costs approximately $€ 80-100(2,3)$.

Despite the fact that Subutex is used to treat opioid dependence, its utilization in the form observed in Georgia is extremely harmful. Subutex is used through injection of non-sterile pills, which are dissolved in boiled water and injected intravenously. As a rule, in Georgia, Subutex is used in groups. The solution is 
usually made in one vessel and is shared by several users. This increases the risk of the spread of HIV/AIDS, hepatitis etc. Since Subutex does not have a strong euphoric effect, different psychotropic substances (antihistamines, sedatives) are added to Subutex to strengthen the effect, which turns Subutex use into poly-drug addiction. After long-time use of Subutex, especially in combination with other psychotropic substances, abstinence is marked with heavy symptoms, especially with dysphoria and depression. Subutex is especially popular among young drug users.

Although Georgia is considered to have a low HIV/AIDS prevalence, there are still some alarming trends. The main route of HIV transmission is injective drug use (62-65\%) (Fig. 2). Although the prevalence of HIV/AIDS among IDUs is only 1-3\%, the very high number of IDUs and high prevalence of hepatitis $\mathrm{C}$ in this population could be the predictor of an HIV increase if appropriate prevention measures are not taken in time (4).

Unfortunately, drug treatment funding and appropriate facilities are limited and for the last years free drug treatment programmes haven't existed at all in Georgia. In this situation opioid substitution therapy (OST), as part of a comprehensive programme to provide addiction treatment, is the method that could most quickly and effectively improve situation in the country.

As in most post-soviet countries, high resistance to substitution treatment has occurred in the Georgian society. However, it has been legalized and pilot level programmes have begun. Since 1995

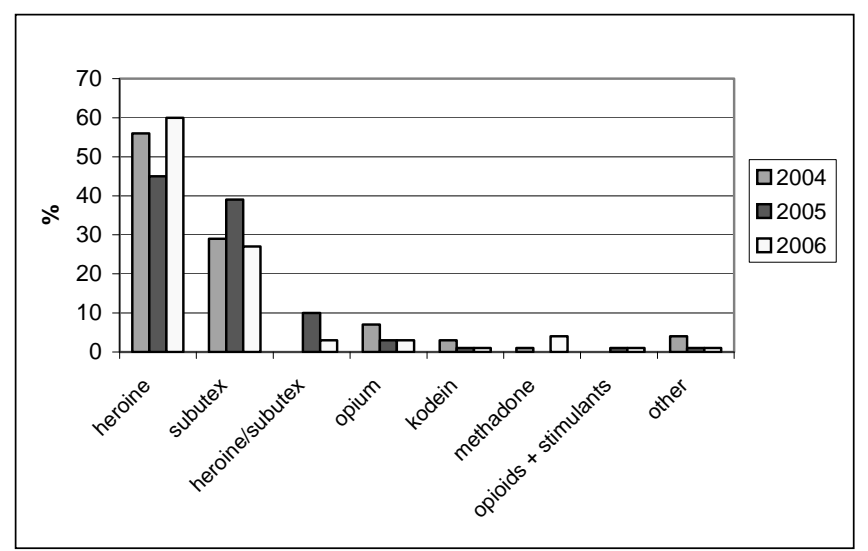

Fig. 1. Drugs used by patients before detoxification. The data are provided by Research Institute on Addiction.

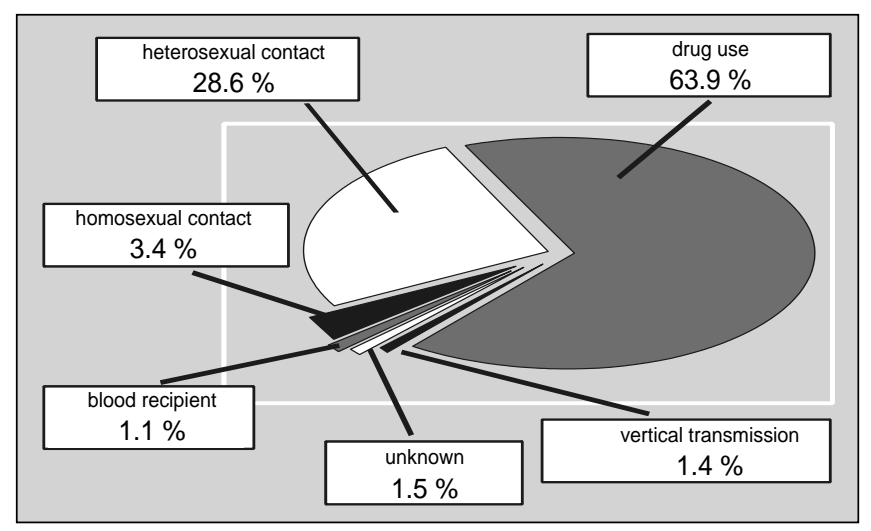

Fig. 2. Main routes of HIV transmission among officially registered HIV positive subjects in Georgia. the Research Institute on Addiction has been advocating for the implementation of OST programmes. After long and severe debates in 2002 the Georgian Parliament adopted a law that permits substitution therapy in the country, however there was no funding for the implementation of this kind of service. Not until the end of 2005 the first methadone substitution therapy programme started in the framework of a GFATM project.

At present, three centres are providing OST - two in Tbilisi, the capital of Georgia and one in Batumi, which serves the Adjara region, one of the most affected territories in terms of the spread of drug addiction and HIV/AIDS. Today the number of same-time beneficiaries of the methadone maintenance therapy programme (MMT) is 230.

\section{MATERIALS AND METHODS}

\section{Selection Criteria}

The patients are selected on the basis of opioid dependence substitution therapy methodology, which was established by the minister of health. The criteria for the inclusion into the programme are the following:

1. Diagnosis of opioid dependence syndrome (active dependence) along with at least one of the criteria included in point 2 .

2. a) Minimum age 25; minimum 3 years of the utilization of opioid group drugs, along with at least 1 year utilization of intravenous drugs; at least one unsuccessful previous attempt to treat opioid dependence with other methods.

b) HIV infection, AIDS.

c) Pregnancy.

d) In case of the presence of other special clinical and social indicators, decision of a supervisor's board, as an exception.

Since the start of programmes 281 patients have received OST (276 men and 5 women). Among them, 45 patients have been diagnosed as HIV positive. Actually all people living with HIV and with an opioid dependence living in Tbilisi and Adjara willing to receive OST, were included in the programmes. Doctors, psychologists and social workers are involved in the realization of OST programmes.

\section{Characteristics of Programmes}

Main characteristics of OST programmes in Georgia are the following:

- OST programmes provide complex medico-psychological support with elements of social rehabilitation.

- Most patients are on maintenance therapy.

- Average daily dose of methadone is 60-70 mg.

- Monitoring of other narcotic/psychotropic drug use is systematically conducted.

- Exclusion of patients from the programmes is very rare and mostly due to strict abolishment of the regime.

In 200660 opioid dependent patients receiving MST and psychosocial support were studied at the Research Institute on Addiction, Tbilisi. Level of depression [Beck Depression Inventory (5)], anxiety [Spielberger Anxiety Inventory(6)], quality of life [questionnaire that was used in WHO research studies(7)] and other data were measured before starting MST and after 3, 6 and 12 months. The illegal use of psychotropic-narcotic sub- 
stances was checked through random urine-testing 3 times per patient and month.

\section{RESULTS}

The study showed significant improvement of patient's psychosocial state (Fig. 3, 4). The decrease of depression and anxiety was observed (dynamic of average scores of depression were 25, 16, 13, 13; dynamic of average scores of anxiety: 49, 40, 40 and 41). Life quality increased in comparison with the starting data (69, 84, 91, and 85). The positive answers on psychotropic-narcotics were observed in 5.6 people per month on average.

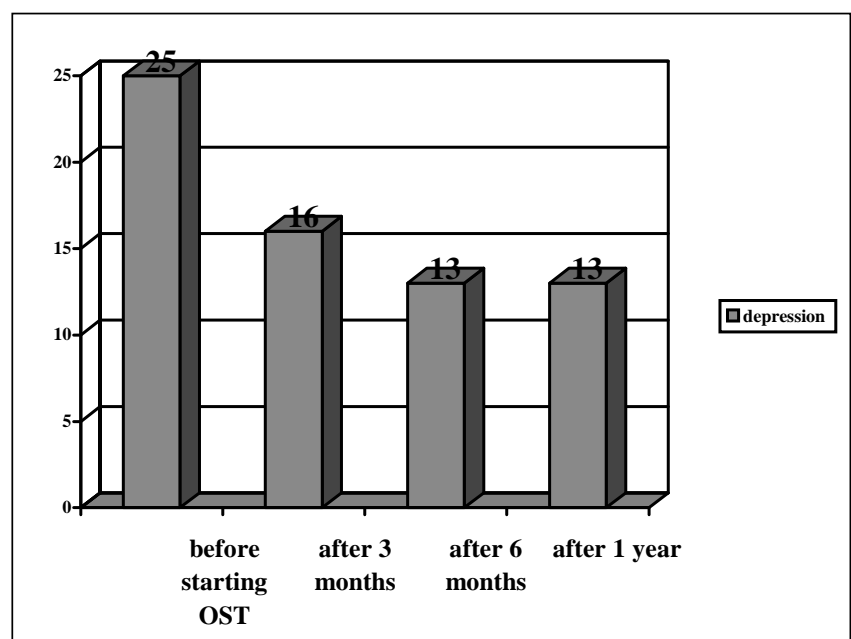

Fig. 3. Dynamic of depression in patients of OST programme at the Research Institute on Addiction, Tbilisi.

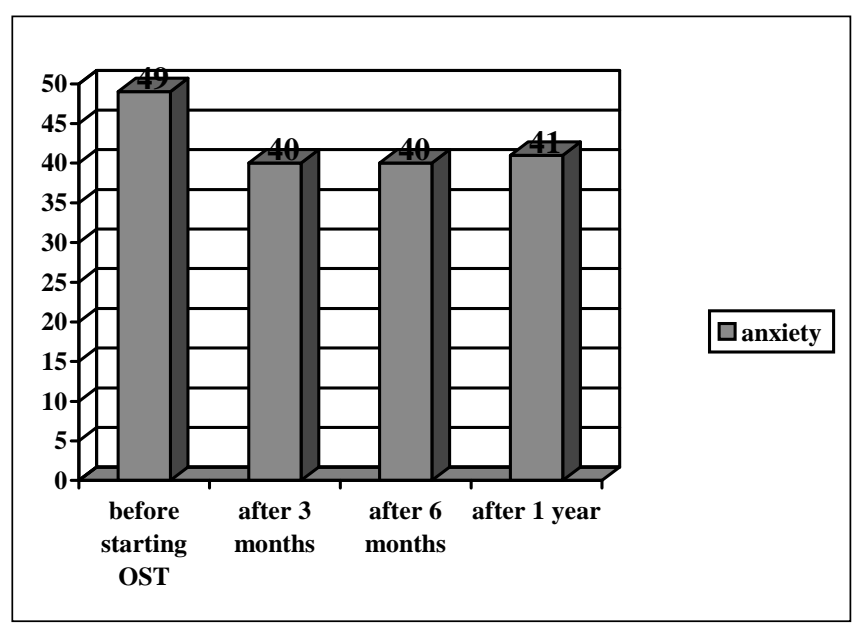

Fig. 4. Dynamic of anxiety in patients of OST programme at the Research Institute on Addiction, Tbilisi.
Our incomplete 2-year experience has shown the following results:

- High compliance of therapy

- Significant improvement of health and life quality.

- Marked increase of the degree of resocialization.

- Significant decrease of criminal activity.

- Minimization of illegal narcotic drug use.

- Significant diminishment of drug-related risky behavior.

- Very small number of subjects willing to discontinue participation in OST programmes.

\section{CONCLUSIONS}

As the analysis of the health and psychosocial status of patients involved in methadone substitution programmes has revealed, in Georgia as well as in other countries, this method of treatment is very efficient. We are convinced that the increased number of patients participating in substitution programmes in Georgia and the expansion of programmes geographically may have a very positive influence upon the health and social climate inside the country. It will not only support the efforts to limit the further spread of drug use, HIV/AIDS, and hepatitis C, but will also reduce drug-related crime.

\section{REFERENCES}

1. SCAD Georgia [homepage on the Internet]. Tbilisi : SCAD Programme. Drug situation in Georgia 2003: annual report [cited 2007 Dec 17]. Available from: http://www.scad.ge.

2. SCAD Georgia [homepage on the Internet]. Tbilisi : SCAD Programme. Drug situation in Georgia 2005: annual report [cited 2007 Dec 17]. Available from: http://www.scad.ge.

3. Parfitt T. Designer drug Subutex takes its toll in Tbilisi. Lancet. 2006 Jul 22;368(9532):273-4.

4. Stvilia K, Todadze Kh, Nizaradze G. HIV/AIDS in Georgia. In: Twigg JL, editor. HIV/AIDS in Russia and Eurasia. New York: Palgrave Macmillan; 2006.

5. Beck AT, Steer RA, Brown GK. Manual for the Beck Depression Inventory-II. San Antonio: Psychological Corporation; 1996.

6. Spielberger GD, Gorush RL, Lusshene RE. The state-trait anxiety inventory. Palo Alto: Consulting Psychologists Press; 1970.

7. World Health Organization [homepage on the Internet]. Geneva: WHO Quality of Life-BREF [cited 2007 Dec 17]. Available from: http://www. who.int/substance_abuse/research_tools/en/.

Received December 17, 2007 Accepted in revised form May 29, 2008 